\title{
Electrochemical determination of acetaminophen at a carbon electrode modified in the presence of $\beta$-cyclodextrin: role of the activated glassy carbon and the electropolymerised $\beta$-cyclodextrin
}

\author{
Bronach Healy ${ }^{1}$. Francesco Rizzuto ${ }^{1} \cdot$ Marida de Rose ${ }^{1} \cdot$ Tian Yu $^{1} \cdot$ Carmel B. Breslin $^{1}(\mathbb{D}$
}

Received: 5 July 2021 / Revised: 28 August 2021 / Accepted: 30 August 2021 / Published online: 8 September 2021

(c) The Author(s) 2021

\begin{abstract}
Acetaminophen is a well-known drug commonly used to provide pain relief, but it can also lead to acute liver failure at high concentrations. Therefore, there is considerable interest in monitoring its concentrations. Sensitive and selective acetaminophen electrochemical sensors were designed by cycling a glassy carbon electrode (GCE) to high potentials in the presence of $\beta$-CD in a phosphate electrolyte, or by simply activating the GCE electrode in the phosphate solution. Using cyclic voltammetry, adsorption-like voltammograms were recorded. The acetaminophen oxidation product, $\mathrm{N}$-acetyl benzoquinone imine, was protected from hydrolysis, and this was attributed to the adsorption of acetaminophen at the modified GCE. The rate constants for the oxidation of acetaminophen were estimated as $4.3 \times 10^{-3} \mathrm{~cm}^{2} \mathrm{~s}^{-1}$ and $3.4 \times 10^{-3} \mathrm{~cm}^{2} \mathrm{~s}^{-1}$ for the $\beta$-CDmodified and -activated electrodes, respectively. Using differential pulse voltammetry, the limit of detection was calculated as $9.7 \times 10^{-8} \mathrm{M}$ with a linear concentration range extending from 0.1 to $80 \mu \mathrm{M}$. Furthermore, good selectivity was achieved in the presence of caffeine, ascorbic acid and aspirin, enabling the determination of acetaminophen in a commercial tablet. Similar electrochemical data were obtained for both the $\beta$-CD-modified and activated GCE surfaces, suggesting that the enhanced detection of acetaminophen is connected mainly to the activation and oxidation of the GCE. Using SEM, EDX and FTIR, no evidence was obtained to indicate that the $\beta$-CD was electropolymerised at the GCE.
\end{abstract}

Keywords Acetaminophen - Electrochemical sensor $\cdot \beta$-cyclodextrin $\cdot$ Glassy carbon activation · Electropolymerisation . Caffeine $\cdot$ Ascorbic acid

\section{Introduction}

Acetaminophen, also commonly known as paracetamol, is an analgesic and antipyretic drug that is frequently used to reduce fever and provide pain relief [1], with good cardiovascular, renal and gastrointestinal safety when taken at the recommended doses. As it is unable to inhibit the function of the cyclooxygenase (COX) enzyme in the peripheral tissues, it has poor anti-inflammatory properties, but this can be advantageous over the nonsteroidal anti-inflammatory drugs (NSAIDs), such as aspirin [2]. Once acetaminophen is ingested, deacetylation begins and occurs to give the primary

Carmel B. Breslin

Carmel.Breslin@mu.ie

1 Department of Chemistry, Maynooth University, Maynooth, Co. Kildare, Ireland amine, 4-aminophenol. This molecule, while implicated in the formation of an endogenous cannabinoid, which activates the cannabinoid CB1 receptors to give pain relief [2], is also linked to the toxic effects of acetaminophen [3]. With the excessive accumulation of acetaminophen and 4-aminophenol, acute liver failure can occur. Therefore, the concentration of acetaminophen in pharmaceutical formulations is highly controlled and regulated. Various analytical methods are employed in the analysis of acetaminophen-containing formulations [4], including chromatography [5] and various spectroscopy techniques $[6,7]$. While all these techniques can be employed successfully, they are not always suitable for routine analysis, with high equipment costs, time-consuming analyses, and in some cases poor selectivity and low sensitivity is observed. Acetaminophen is readily oxidised through a two electron two proton transfer reaction at potentials considerably lower than the oxygen evolution reaction at most electrodes to form $\mathrm{N}$-acetyl 
benzoquinone imine [8]. Accordingly, there is considerable interest in the development of electrochemical sensors that can be employed in the detection and analysis of acetaminophen.

Various materials have been employed to give sensitive and selective electrochemical sensors for the determination of the concentration of acetaminophen, with carbon-based materials, including graphene [9-13], graphite [14, 15], carbon nanotubes $[8,16]$ and mesoporous carbon [17] featuring in several studies. For example, Kachoosangi et al. [15] utilised plane pyrolytic graphite electrodes modified with carbon nanotubes, Li et al. [18] combined Pd with graphene oxide to give a nanocomposite, while Li et al. [8] employed multi-walled carbon nanotubes for the simultaneous electrochemical detection of acetaminophen, tyrosine and levodopa. Enhanced detection of acetaminophen has also been observed with the covalent modification of carbon-based electrodes, using for example diazonium cations [19] and 4-amino benzoic acid [20]. In addition, various metal nanoparticles and metal oxides/hydroxides have been utilised, including palladium [18, 21, 22]; nickel and copper [23, 24]; titanium oxide [11, 13]; iron oxide [25]; zinc oxide [26]; tungsten oxide [27]; cobalt [28]; gold [29, 30]; perovskitetype oxides [31]; and doped nanoparticles, such as nickeldoped cobalt ferrite nanoparticles [32]. While these sensors have been effectively used in the electrochemical detection of acetaminophen, there is always the risk of carbon nanotubes, graphene flakes and metal nanoparticles leaching from the sensor surface. This not only results in a loss in the performance of the sensor, but can result in the release of nanomaterials into the environment.

In recent times, cyclodextrins, which are well known as supramolecular systems [33], have been employed in the fabrication of sensors. These supramolecular systems can be incorporated as anionic dopants within conducting polymers [34], adsorbed onto surfaces [35] or more commonly combined with other materials to generate a slurry or suspension that can be used to modify the electrode surface [36, 37]. Furthermore, there has been considerable interest in the electropolymerisation of $\beta-\mathrm{CD}$ [38-40]. However, this electropolymerisation approach involves cycling the GCE to relatively high potentials in the presence of acidic solutions, where the GCE becomes oxidised and activated [41]. This oxidation leads to the formation of oxygen-containing functional surface groups, and these have been reported at glassy carbon [42], carbon nanotubes [43] and activated carbon [44]. Their presence can lead to a considerable increase in the rate of the electron transfer step $[42,45]$.

In this paper, results are presented on the attempted electropolymerisation of $\beta$-cyclodextrin ( $\beta$-CD) in a phosphate buffer solution at GCE and, for comparative purposes, similar experiments were carried out in the absence of the cyclodextrin. In both cases, conducting surfaces were generated, providing very simple electrochemical sensors for acetaminophen. Using acetaminophen as a well-studied analyte, the roles of both the $\beta$-cyclodextrin and the activation of the GCE substrate were explored.

\section{Experimental}

All chemicals, including acetaminophen, $\beta-C D$, sulfonated $\beta$-CD, caffeine, ascorbic acid, aspirin, uric acid, sorbate and phosphate salts were obtained as Analar grade reagents from Sigma-Aldrich and used without any further purification. A glassy carbon rod electrode (GCE) (3 $\mathrm{mm}$ in diameter) was used in all experiments. This rod was embedded in epoxy resin and then inserted into a Teflon holder with electrical contact being achieved by means of a copper plate at the base of the carbon sample. Prior to each experiment, the GCE surface was polished to a mirror finish, using successively smaller sizes of diamond paste down to a $1-\mu \mathrm{m}$ particle-sized paste. The electrode was then rinsed with distilled water and finally cleaned in an ultrasonic bath. A platinum wire was used as an auxiliary electrode and a saturated calomel electrode (SCE) was used as the reference electrode in the voltammetry experiments, while a silver-silver chloride reference electrode was employed in the differential pulse voltammetry (DPV) experiments.

A Hitachi S-3200-N scanning electron microscope with a tungsten filament was used to study the morphology of the $\beta$-CD-modified GCE and activated GCE, while energy dispersive X-ray (EDX) analyses were carried out using an Oxford Instrument INCAX-act EDX system. ATR-FTIR data were collected using a Varian FTS-7000 FTIR spectrometer equipped with a Pike Miracle ATR diamond crystal. All samples were thoroughly rinsed and dried before analysis.

The cyclic voltammetry data were recorded using a Solartron 1287 potentiostat, while the DPV experiments were performed using a CHI potentiostat. All measurements were recorded at room temperature. Unless otherwise stated, the $\beta$-CD-modified GCE was formed by cycling the GCE from -2.0 to $2.2 \mathrm{~V}$ vs. SCE in a solution of $5 \mathrm{mM} \beta-\mathrm{CD}$ with a phosphate buffer ( $\mathrm{pH}$ of 5.5 ) at $100 \mathrm{mV} \mathrm{s}^{-1}$ for 20 cycles. The concentration of $\beta$ - $\mathrm{CD}(5 \mathrm{mM})$ is below the solubility limit at room temperature. Therefore, during electropolymerisation, the solutions were not agitated to disperse insoluble $\beta$-CD particles, a process that has been employed in previous studies [38]. A similar approach was used for the activation of the GCE, with the electrode being polarised in a slightly acidic solution between the same potential limits of -2.0 to $2.2 \mathrm{~V}$ vs. SCE for 20 cycles. The modified electrodes were then thoroughly rinsed with distilled water and transferred to the buffer and cycled for 2 cycles before cycling in the acetaminophen-containing solution. Unless otherwise stated, a phosphate buffer solution, at a pH of 7.0, was used in the electrochemical detection of acetaminophen. 
The DPV experiments were recorded at the optimised conditions which were found to be a pulse amplitude of $50 \mathrm{mV}$, a pulse width of $0.055 \mathrm{~s}$, a sampling width of $0.0167 \mathrm{~s}$, a pulse period of $0.5 \mathrm{~s}$ and an increment of $4 \mathrm{mV}$. The experiments were repeated at least 3 times and the standard error $(\mathrm{SE}=$ $\left.\rho / n^{1 / 2}\right)$ is shown as error bars on the relevant plots.

\section{Results and discussion}

\section{Formation and characterisation of the $\beta$-CD-modified GCE and the activated GCE}

The attempted electropolymerisation of $\beta$-CD was performed by cycling the electrode from -2.0 to $2.2 \mathrm{~V}$ vs. SCE in a slightly acidified phosphate buffer $(\mathrm{pH}=5.5)$ solution with a $5 \mathrm{mM} \beta-\mathrm{CD}$ solution. This resulted in the formation of a dark coloured film, in agreement with previous studies [38]. For the phosphate buffer system containing $\beta-C D$ (Fig. 1(a)), two anodic peaks are observed at about $0.6 \mathrm{~V}$ and $1.6 \mathrm{~V}$ vs. SCE and these increase in intensity with increasing cycle number. A clear reduction wave is evident at approximately $-0.6 \mathrm{~V}$ vs. SCE and again this peak increases with increasing cycle number. The electropolymerisation of $\beta$ $\mathrm{CD}$ has been described in terms of the initial adsorption of the $\beta$-CD at the carbon electrode followed by the formation of radical cations on the application of relatively high potentials, which gives rise to the coupling of the adsorbed molecules and the formation of the deposited polymeric structure [38]. Indeed, the cathodic peak at $-0.6 \mathrm{~V}$ vs. SCE has been directly related to the extent of polymerisation [38].

However, as shown in Fig. 1(b), nearly identical voltammograms were obtained on cycling the GCE in the phosphate solution without the presence of the $\beta$-CD. This cycling activates the GCE, with alterations to its microstructure, the formation of new active edge planes, the formation of a graphite oxide layer and the formation of oxygen-containing functional groups. Instead, it appears that the reduction peak at about $-0.6 \mathrm{~V}$ is connected with the reduction of oxides formed during the cycling of the GCE to these relatively high potentials. The peak currents associated with this reduction event increase with cycling while the peak potentials become slightly more negative with continued cycling. It has also been shown that the supporting electrolyte plays a role in the activation process [41] and this can be seen in Fig. 1(c), where the GCE was cycled in the presence of $\beta$-CD with chloride and sulfate as the supporting electrolytes. Again, identical voltammograms were recorded in the absence of the $\beta-C D$, suggesting that the redox peaks observed are connected with the oxidised and activated GCE. The voltammogram recorded in the chloridecontaining solution is very different to that observed in the
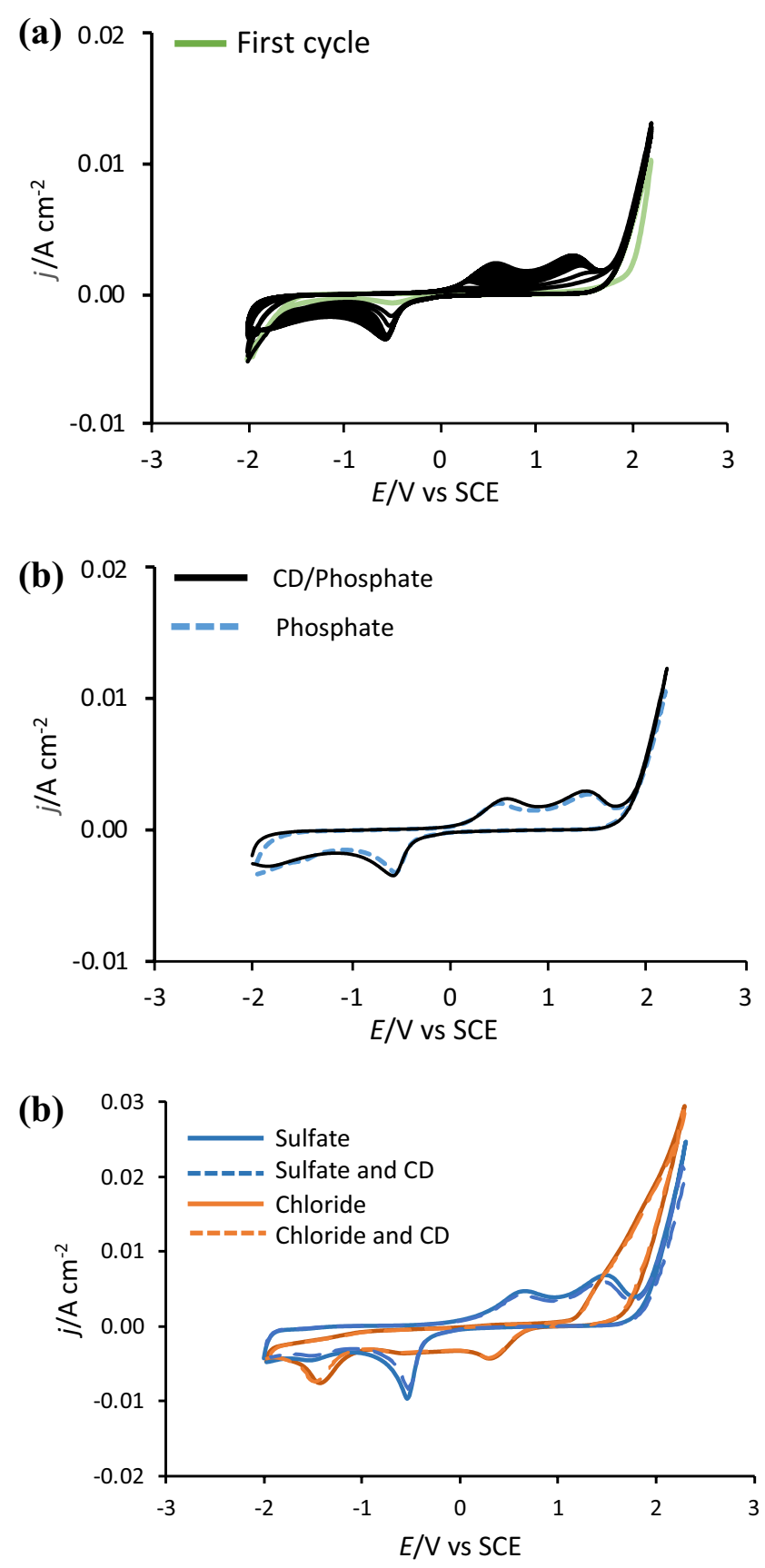

Fig. 1 Cyclic voltammograms recorded at $100 \mathrm{mV} \mathrm{s}^{-1}$ in a $5 \mathrm{mM} \beta$ $\mathrm{CD}$ and $0.1 \mathrm{M}$ phosphate, cycles 1 to $20, \mathbf{b} 20^{\text {th }}$ cycle in $5 \mathrm{mM} \beta-\mathrm{CD}$ with $0.1 \mathrm{M}$ phosphate and in $0.1 \mathrm{M}$ phosphate and $\mathbf{c}$ in the presence and absence of $5 \mathrm{mM} \beta-\mathrm{CD}$ in $0.1 \mathrm{M} \mathrm{NaCl}$ and $0.05 \mathrm{M} \mathrm{Na}_{2} \mathrm{SO}_{4}$

phosphate or sulfate solutions. The characteristic oxidation waves seen prior to the oxygen evolution reaction with the phosphate and sulfate systems are no longer evident, while more pronounced reduction waves appear during the reverse cycle. The onset of the oxygen evolution reaction occurs at a lower overpotential in the chloride-containing solution. This is a complex reaction, involving the formation of 
adsorbed species, $\mathrm{OH}^{\bullet}$ radicals and the evolution of gaseous molecules. Moreover, the $\mathrm{C}^{-}$ions can combine with the $\mathrm{OH}^{\bullet}$ species to give various reactive intermediates, such as $\mathrm{ClOH}^{\bullet-}$ [46]. Therefore, the earlier onset of this reaction in the presence of the chloride solution is likely to alter both the activation of the GCE electrode and the adsorption and possible electropolymerisation of the $\beta$-CD molecules. In addition, the adsorption of the chloride, phosphate and sulfate anions at the GCE may also play a role in this activation process.

In an attempt to further understand the role of the $\beta$-CD and the activated GCE surface, ATR-FTIR and SEM/EDX were employed. Representative FTIR data are shown in Fig. 2, where the spectrum of $\beta-C D$ is compared with the $\beta$-CD-modified and activated GCE. In terms of the $\beta$-CD, the symmetric and antisymmetric stretching of $\mathrm{O}-\mathrm{H}$ is evident as a broad peak centred at $3230 \mathrm{~cm}^{-1}$, while bands for $\mathrm{C}-\mathrm{H}$ stretching at $2930 \mathrm{~cm}^{-1}, \mathrm{C}-\mathrm{O}$ stretching at $1038 \mathrm{~cm}^{-1}$, $\mathrm{C}-\mathrm{O}-\mathrm{C}$ stretching at $1153 \mathrm{~cm}^{-1}$, and bending vibrations of $\mathrm{O}-\mathrm{H}$ at $1028 \mathrm{~cm}^{-1}$, are also seen. The spectra recorded for the activated GCE and $\beta$-CD-modified GCE are very similar. In this case, the broad bands in the region from 3000 to $3400 \mathrm{~cm}^{-1}$ can be attributed to $\mathrm{O}-\mathrm{H}$ stretching vibrations, and these may indicate the presence of edge and basal hydroxyls. The bands in the vicinity of 1400 to $1800 \mathrm{~cm}^{-1}$ can be assigned to oxidised groups, such as carbonyl, ketones and carboxyl groups [47]. In particular, the band at $1056 \mathrm{~cm}^{-1}$ can be ascribed to $\mathrm{C}-\mathrm{OH}$ stretching vibrations, the band at $1650 \mathrm{~cm}^{-1}$ can be related to $\mathrm{C}=\mathrm{C}$ stretching and the vibration at $1214 \mathrm{~cm}^{-1}$ is characteristic of $\mathrm{C}-\mathrm{O}-\mathrm{C}$. The band at $1200 \mathrm{~cm}^{-1}$ can be attributed to phenolic species, while bands at lower wavenumbers are consistent with $\mathrm{C}=\mathrm{C}$ bending modes. While there are some similarities between the FTIR data recorded with the $\beta-\mathrm{CD}$ and the $\beta$-CD-modified electrode, it is difficult to prove the presence of the electropolymerised $\beta$-CD. In both cases, similar

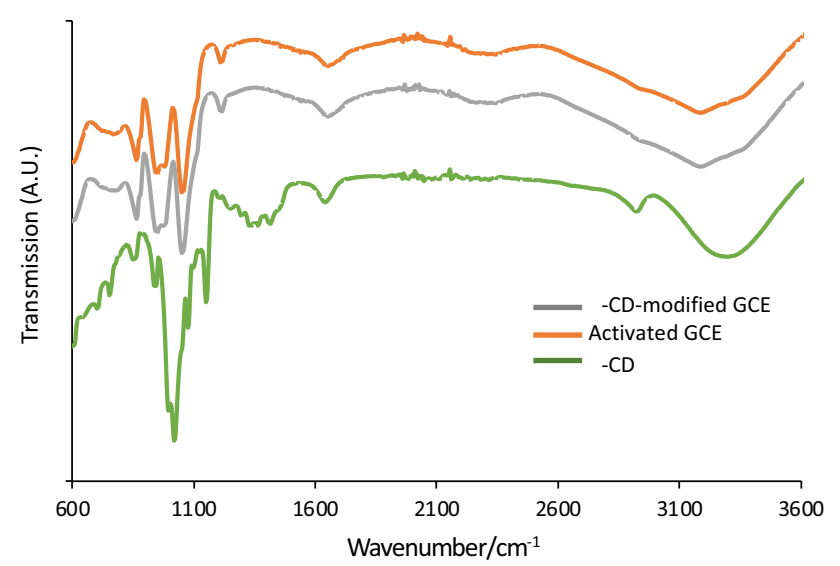

Fig. 2 FTIR data recorded for $\beta$-CD (green), $\beta$-CD-modified (grey) and activated GCE (orange) functional groups, for example, $\mathrm{C}-\mathrm{O}$ and $\mathrm{O}-\mathrm{H}$ contribute to the observed vibrations, while the spectra recorded for the activated and $\beta$-CD-modified electrode are nearly identical.

Using EDX, an elemental analysis was performed on the activated GCE and $\beta$-CD-modified GCE and these data are summarised in Table 1. Pristine GCE was used as a control, giving an elemental analysis of $100 \%$ carbon; however, all the other modified GCE surfaces exhibited significant oxygen content. An oxygen content approaching 30\% was observed for the activated and $\beta$-CD-modified GCE, while a somewhat lower value of $12 \%$ was achieved using a sulfonated $\beta-\mathrm{CD}$. This sulfonated $\beta-\mathrm{CD}$ was employed as it easily detected using EDX. Interestingly, no sulfur was detected when this $\beta$-CD (with $12-15 \mathrm{OH}$ groups replaced with $\mathrm{SO}_{3}{ }^{-}$groups) was added to the phosphate solution, clearly showing that it is not electropolymerised at the GCE. The electropolymerisation of this sulfonated $\beta-C D$ may be slower that the unsubstituted $\beta-\mathrm{CD}$, but it should nevertheless polymerise, given its good solubility with some free $\mathrm{OH}$ groups. The lack of a sulfur signal suggests that oxidation of the GCE surface is the main reaction that occurs during the cycling of the GCE in the phosphate solution. Possible reaction pathways have been previously proposed in the literature leading to the formation of ketones, carbonyl, aldehydes and carboxylic groups. For example, Yi et al. [47] have suggested that the electrophilic addition of water occurs at the carbon conjugated $\Pi$-system in acidic solutions, and this is then followed by oxidation and condensation steps. The slightly acidic phosphate buffer at a pH of 5.5 used in Fig. 1, appears to be sufficiently acidic to facilitate these events.

Typical SEM micrographs recorded after cycling the GCE at $100 \mathrm{mV} \mathrm{s}^{-1}$ in the phosphate buffer in the presence and absence of the $\beta-C D$ between the potential limits of -2.0 and $2.2 \mathrm{~V}$ vs SCE are shown in Fig. 3(a) and (b), respectively. On comparing these to the pristine GCE, Fig. 3(e), it is evident that the surface is rougher with cracked-like features more evident on cycling in the phosphate solution without the presence of the $\beta-C D$. There is no clear evidence to suggest that the $\beta$-CD has electropolymerised at the GCE; however, the globules seen in Fig. 3(a) may be connected with $\beta$-CD deposits. On decreasing the scan rate between the potential intervals of -2.0 and $2.2 \mathrm{~V}$ to $50 \mathrm{mV} \mathrm{s}^{-1}$, the

Table 1 Elemental analysis obtained for GCE cycled in $0.1 \mathrm{M}$ phosphate buffer for 20 cycles at $50 \mathrm{mV} \mathrm{s}^{-1}$ from -2.0 to $2.2 \mathrm{~V}$ vs. SCE and in the presence of $5 \mathrm{mM} \beta-\mathrm{CD}$ and $5 \mathrm{mM}$ sulfonated $\beta-\mathrm{CD}$. Data averaged over 5 sites on the surface

\begin{tabular}{llc}
\hline Sample & \%Carbon & \%Oxygen \\
\hline Pristine GCE & 100 & - \\
Activated GCE & $70.8 \pm 2.3$ & $29.1 \pm 1.9$ \\
$\beta-C D / G C E$ & $75.3 \pm 1.9$ & $24.4 \pm 1.5$ \\
Sulfonated $\beta$-CD/GCE & $87.6 \pm 0.3$ & $12.3 \pm 0.3$ \\
\hline
\end{tabular}


Fig. 3 SEM micrographs recorded for GCE formed in $0.1 \mathrm{M}$ phosphate between -2.0 and $2.2 \mathrm{~V}$ vs. SCE in the a presence of $5 \mathrm{mM} \beta-\mathrm{CD}$ at $100 \mathrm{mV} \mathrm{s}^{-1}$ and $\mathbf{b}$ absence of $\beta-\mathrm{CD}$ at $100 \mathrm{mV} \mathrm{s}^{-1}$, c presence of $5 \mathrm{mM} \beta-\mathrm{CD}$ at $50 \mathrm{mV} \mathrm{s}^{-1}$, d absence of $5 \mathrm{mM} \beta-\mathrm{CD}$ at $50 \mathrm{mV} \mathrm{s}^{-1}$ and e pristine GCE before cycling
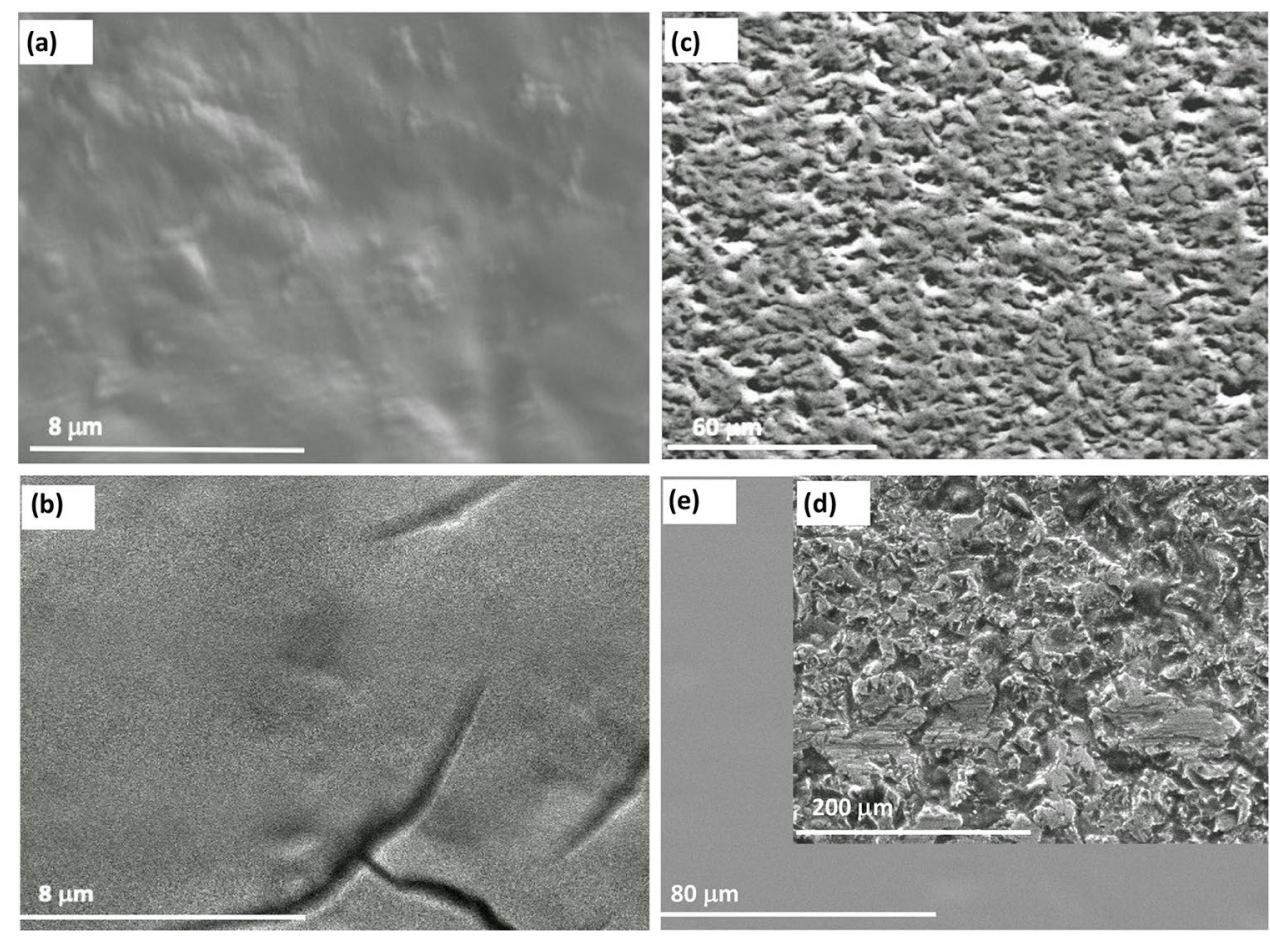

surface morphology becomes very different, as illustrated in Fig. 3(c). In this case, the GCE adopts an etched-like surface, consistent with dissolution of the GCE. Although the surface morphologies in the phosphate solution are similar to that obtained in the $\beta$-CD-containing phosphate electrolyte, more extensive etching is seen in the absence of the $\beta$ $\mathrm{CD}$. This may indicate that the $\beta-\mathrm{CD}$ protects the surface to some extent when cycled to these high potentials. These data are consistent with a study by Yi et al. [47] who concluded that degradation of the GCE occurred by ring opening in the graphitic structure with the formation of oxides.

\section{Redox behaviour of acetaminophen at $\beta$-CD-modified and activated GCE}

The performance of the modified GCE surfaces in the oxidation of acetaminophen was investigated using the electrodes modified in the chloride, sulfate and phosphate solutions.
The best detection was observed using the phosphate system, while as expected the chloride-based system gave the lowest peak currents (data not shown). In Fig. 4(a), the voltammograms recorded for the modified electrodes, generated by cycling in the phosphate solution in the presence and absence of the $\beta-\mathrm{CD}$, and the unmodified GCE are compared. The typical irreversible diffusion-controlled behaviour of acetaminophen is evident for the unmodified GCE, with a broad oxidation wave centred at about $0.55 \mathrm{~V}$ vs. SCE. Furthermore, the corresponding reduction peak is absent, indicating a slow irreversible redox reaction. This is consistent with the formation of $\mathrm{N}$-acetyl benzoquinone imine, which then undergoes a hydrolysis reaction, as illustrated in Scheme 1.

In contrast, the peak oxidation waves appear at considerably lower overpotentials, centred at approximately 0.35 vs. SCE, for the modified GCE surfaces. Furthermore, the anodic peak currents are significantly higher,
Fig. 4 Cyclic voltammograms recorded at $100 \mathrm{mV} \mathrm{s}^{-1} \mathrm{scan}$ ning from -0.2 to $1.0 \mathrm{~V}$ in $1.0 \mathrm{mM}$ acetaminophen in a neutral phosphate buffer at a GCE, activated GCE and at $\beta-\mathrm{CD} / \mathrm{GCE}$ and $\mathbf{b}$ extended activation period, with $\beta-\mathrm{CD} / \mathrm{GCE}$ formed by cycling between -2.0 and $2.2 \mathrm{~V}$ vs. SCE at $50 \mathrm{mV} \mathrm{s}^{-1}$ for 20 cycles
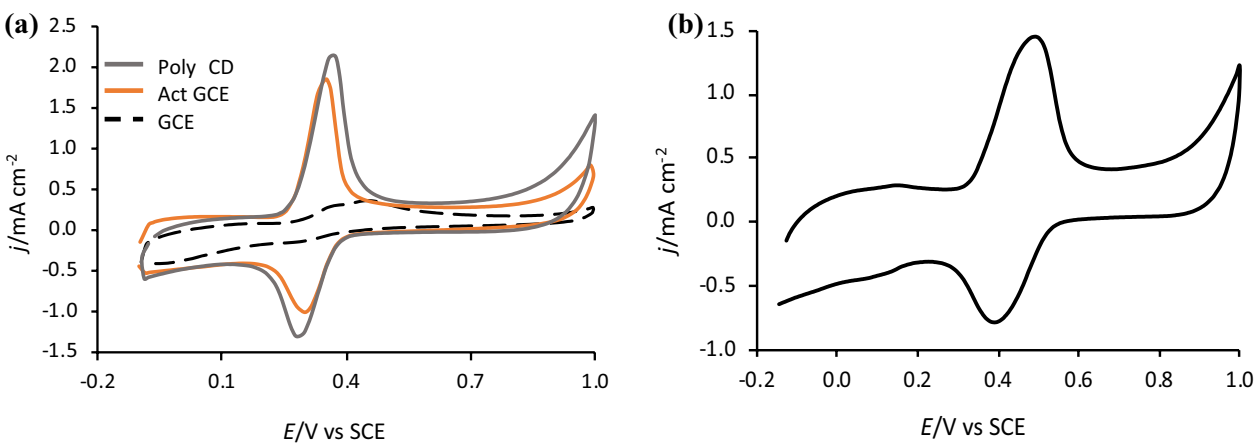
<smiles>CO[N+]([14CH3])=C1C=CC(=O)C=C1</smiles><smiles>C[In](C)O</smiles>

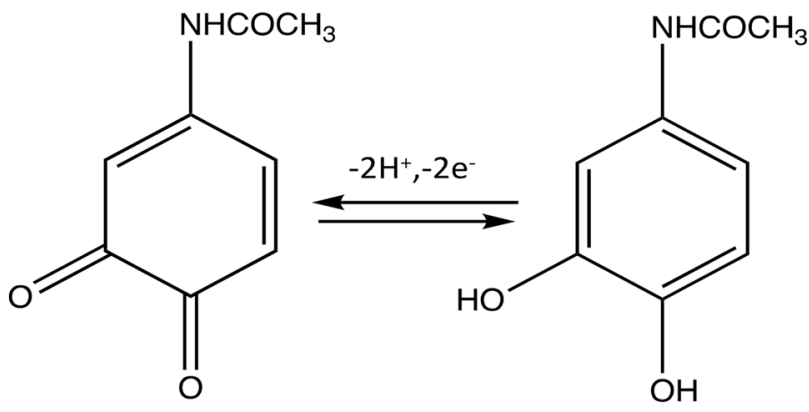

Scheme 1 Oxidation of acetaminophen

reaching values of approximately $1.95 \pm 0.08 \mathrm{~mA} \mathrm{~cm}^{-2}$ and $1.78 \pm 0.09 \mathrm{~mA} \mathrm{~cm}^{-2}$ for the $\beta-\mathrm{CD} / \mathrm{GCE}$ and activated GCE, respectively, compared to a much lower current density of about $0.2 \mathrm{~mA} \mathrm{~cm}^{-2}$ for the unmodified GCE. These narrow symmetric redox waves, evident at the $\beta$-CD/GCE and the activated GCE, are consistent with an adsorption-controlled reaction, where the acetaminophen is confined at the surface. However, on extended activation and oxidation of the GCE, achieved by cycling the $\beta-C D$ at a slower scan rate of $50 \mathrm{mV} \mathrm{s}^{-1}$ between the potential limits of -2.0 to $2.2 \mathrm{~V}$ vs. SCE for 20 cycles, lower peak currents, higher peak potentials and wider peaks were seen, as illustrated in Fig. 4(b). This indicates a slower rate of electron transfer. Moreover, higher background currents are evident, with a broad wave emerging in the vicinity of 0.0 to $0.2 \mathrm{~V}$ vs. SCE. This broad wave was also evident on cycling in the phosphate buffer, suggesting that it is associated with surface bound redox groups generated during the extended activation and oxidation of the GCE surface. Indeed, the increased capacitance is consistent with the formation of the highly porous surface layers, seen in Fig. 3(c).

The data presented in Fig. 4(a) are consistent with a surface-confined analyte. The experimental $\Delta E \mathrm{p}$ values, were in the vicinity of $45 \mathrm{mV}$ at slow scan rates, and these peak separations are close to the theoretical value of $0 \mathrm{mV}$ for the reversible electron transfer of an ideally behaved adsorbed species. Moreover, the ratio of $j_{p(\mathrm{ox})} / j_{p(\mathrm{red})}$ is relatively close to unity at the lower scan rates. This indicates that the electrogenerated $\mathrm{N}$-acetyl benzoquinone imine is reasonably stable and not further hydrolysed to any great extent. Therefore, it can be reduced back to acetaminophen. While this conversion of $\mathrm{N}$-acetyl benzoquinone imine to acetaminophen can be observed at high scan rates at a variety of electrodes, it is seen in this case at slow scan rates in the vicinity of $15 \mathrm{mV} \mathrm{s}^{-1}$, suggesting that it is indeed protected from extensive hydrolysis. This protection may be related to its adsorption at both the activated GCE and $\beta-\mathrm{CD} / \mathrm{GCE}$ surfaces. It appears that the electrogenerated edge planes and oxygenated functional groups formed during the activation of GCE facilitate the adsorption of both acetaminophen and $\mathrm{N}$-acetyl benzoquinone imine, while any deposited or electropolymerised $\beta$-CD can also facilitate the formation of an inclusion complex, trapping the acetaminophen and the oxidised product, $\mathrm{N}$-acetyl benzoquinone imine, at the surface.

The relationship between the oxidation peak current and the scan rate for both the $\beta$-CD-modified and activated GCE is shown in Fig. 5. In both cases, linear relationships were obtained. The linear regression equation obtained for the $\beta$-CD-modified GCE was $E_{p} / \mathrm{mV}=(0.015 \pm 0.001)$ $v+(0.225 \pm 0.091) \quad\left(R^{2}=0.98\right)$, compared to $E_{p} /$ $\mathrm{mV}=(0.016 \pm 0.001) v+(0.151 \pm 0.052)\left(R^{2}=0.99\right)$ for the activated GCE, both consistent with the oxidation of acetaminophen being under adsorption control. On plotting the logarithm of the peak current as a function of the logarithm of the scan rate the slopes of the linear plots were obtained
Fig. 5 a Plot of peak current as a function of scan rate and b logarithm of peak current as a function of the logarithm of scan rate, recorded in $1.0 \mathrm{mM}$ acetaminophen, for the $\beta-\mathrm{CD}$ GCE (grey) and activated GCE (orange)
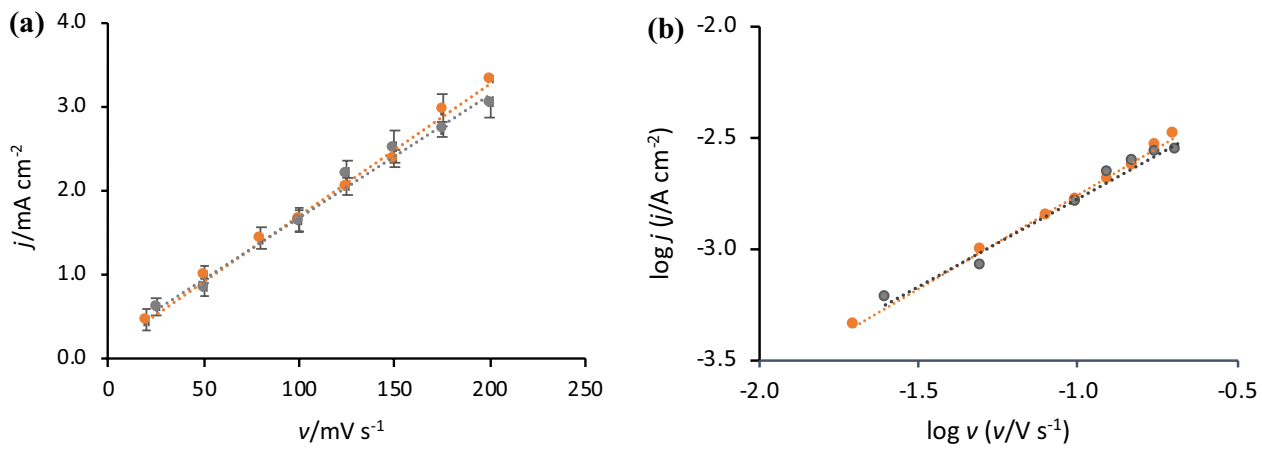
as 0.85 and 0.78 for the activated and $\beta$-CD-modified GCE electrodes, deviating somewhat from the ideal value of 1.0 for adsorption-controlled redox reactions. In particular, the value of 0.78 obtained for the $\beta$-CD-modified electrode suggests mixed control (adsorption and diffusional processes).

The influence of $\mathrm{pH}$ on the oxidation of acetaminophen was studied using DPV and representative plots recorded for the $\beta$-CD-modified electrode at a number of different $\mathrm{pH}$ values are presented in Fig. 6(a). The peak currents become lower in the more alkaline solutions, with a peak current of $1.8 \mathrm{~mA} \mathrm{~cm}^{-2}$ at a $\mathrm{pH}$ of 9.2 , compared to $3.8 \mathrm{~mA} \mathrm{~cm}^{-2}$ at a $\mathrm{pH}$ of 6.5. This may be related to the ionisation of the acetaminophen molecule, which has a $\mathrm{pKa}$ of 9.5 , in the more alkaline solution ( $\mathrm{pH}$ of 9.2). This anionic acetaminophen should have a higher solubility in water and this may reduce its extent of adsorption at the electrode-solution interface. At $\mathrm{pH}$ values lower than 9.2, the acetaminophen will become increasingly more protonated as the solution becomes more acidic. This is consistent with the somewhat higher peak currents observed at a $\mathrm{pH}$ of 6.5 , where the molecule will be neutral (Fig. 6(a)). The variation of the peak oxidation potential with $\mathrm{pH}$ is illustrated in Fig. 6(b). There is a clear linear variation between the $\mathrm{pH}$ and peak potential and the slope of the linear plot is $0.055 \mathrm{~V}$ which is in very good agreement with the Nernst equation. The oxidation of acetaminophen is a $2 \mathrm{e}^{-} / 2 \mathrm{H}^{+}$redox reaction, as illustrated in Scheme 1, and therefore the Nernst equation predicts that the electrode potential is related to $\mathrm{pH}$ with a slope of $0.059 \mathrm{~V}$ at $298 \mathrm{~K}$.

The standard heterogeneous rate constant $\left(k_{s}\right)$ was estimated using Laviron's model, where it is assumed that acetaminophen is irreversibly adsorbed [48]. This relationship is given in Eq. 1, where $E_{p}$ corresponds to the peak potential, $E^{o}$ is the formal potential, $\alpha$ represents the charge-transfer coefficient, $n$ corresponds to the number of electrons transferred, $T$ is the thermodynamic temperature and $F$ is Faraday's constant.

$E_{p}=E^{0}+\left(\frac{R T}{(1-\alpha) n F}\right) \ln \left(\frac{R T k_{s}}{(1-\alpha) n F}\right)-\left(\frac{R T}{(1-\alpha) n F}\right) \ln v$

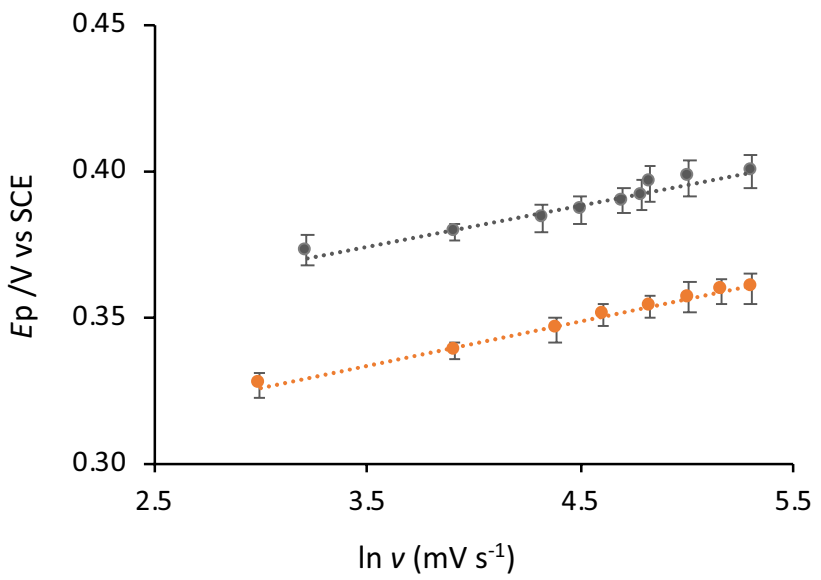

Fig. 7 Plot of $E$ p (oxidation wave) as a function of the logarithm of the scan rate for $\beta$-CD modified GCE (grey symbols) and activated GCE (orange symbols), recorded in $0.5 \mathrm{mM}$ acetaminophen

A typical plot for both the $\beta$-CD-modified and activated GCE is shown in Fig. 7, where good linearity is obtained, indicating good agreement with Eq. 1. The linear regression equation for the $\beta$-CD-modified GCE was obtained as $E_{p} / \mathrm{mV}=(0.0144 \pm 0.0011) \ln v+(0.325 \pm 0.005)$, while the corresponding relationship for the activated GCE was $E_{p} /$ $\mathrm{mV}=(0.0149 \pm 0.0004) \ln v+(0.282 \pm 0.0020)$. An $\alpha$ value of 0.5 , and $E^{0}$ values obtained by plotting $E_{p}$ as a function of $v$ and extrapolating to $v=0$, to give $E^{0}$ values of $370 \mathrm{mV}$ and $325 \mathrm{mV}$ for the $\beta$-CD-modified GCE and activated GCE, respectively, were used in the calculations. Estimated $k_{s}$ values of $(4.3 \pm 0.3) \times 10^{-3} \mathrm{~cm}^{2} \mathrm{~s}^{-1}$ and $(3.4 \pm 0.2) \times 10^{-3} \mathrm{~cm}^{2} \mathrm{~s}^{-1}$ were obtained for the $\beta$-CD-modified and activated GCE, respectively. These values correspond to efficient electron transfer kinetics for both the $\beta-\mathrm{CD}$ and activated GCE electrodes, with a slightly lower rate constant for the activated GCE. While the presence of the $\beta$-CD does not influence the electrochemical data (Fig. 1), it does have some effect on the surface morphology (Fig. 3), protecting the GCE surface from extensive etching. Indeed, as shown in Fig. 4, extensive etching leads to wider peaks, consistent with slower kinetics (Fig. 4(b)). Therefore, this somewhat higher rate constant for
Fig. 6 a Differential pulse voltammograms recorded in $1.0 \mathrm{mM}$ acetaminophen at $\mathrm{pH}$ values of 9.0 (black), 7.5 (orange), 6.5 (purple), 5.1 (green), 3.5 (blue) and 2.1 (grey) and $\mathbf{b}$ corresponding plot of peak potential as a function of $\mathrm{pH}$
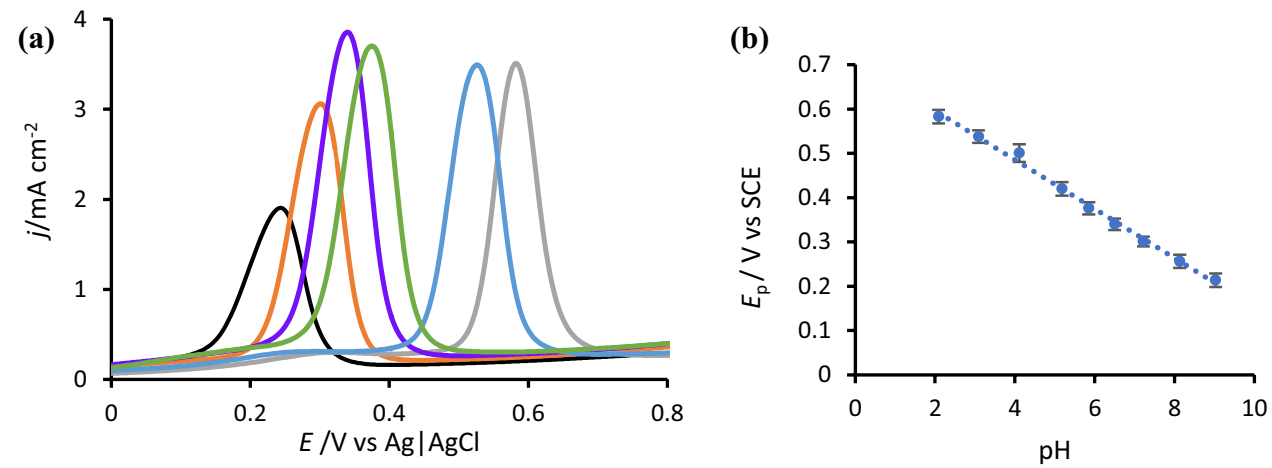
Fig. 8 Calibration curves recorded over $\mathbf{a}$ a wide concentration range and the $\mathbf{b}$ linear range, using DPV data recorded for the $\beta$-CD-modified GCE (grey) and activated GCE (orange)

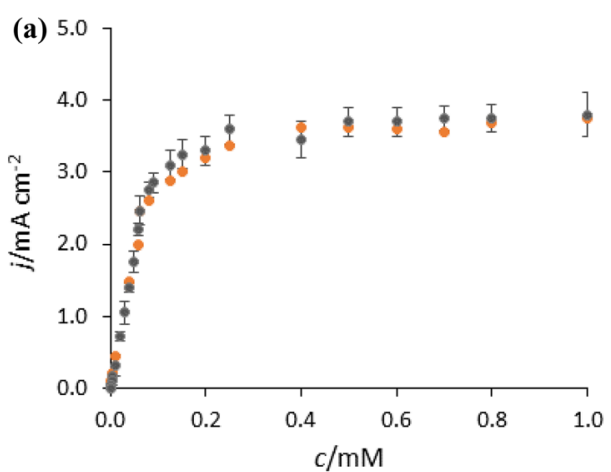

the $\beta$-CD system may be related to the extent of oxidation and the nature of the oxygenated species, or indeed some adsorbed $\beta-\mathrm{CD}$. Using the slope values, and taking $n=2$, $(1-\alpha)$ was computed at 0.84 , giving an $\alpha$ value within the range of 0.0 to 1.0 , but outside the normally expected value between 0.4 to 0.7 .

\section{Sensing performance of the modified GCE electrodes}

The performance of the $\beta$-CD-modified GCE and the activated GCE electrode as a sensor for the detection of acetaminophen was studied using DPV measurements. The resulting calibration curves are presented in Fig. 8. The relationship between the peak oxidation currents recorded using DPV for both the $\beta$-CD-modified GCE and activated GCE are shown in Fig. 8(a), where it is evident that a linear relationship, extending from 0.1 to $80 \mu \mathrm{M}$, is observed at the lower concentrations, while the currents reach a limiting or saturation point with the higher concentrations, to give a curve over the entire concentration range. The linear regression of the calibration curves, shown in Fig. 8(b), were obtained as $I_{p} /$ $\mathrm{mA} \mathrm{cm}{ }^{-2}=(0.0327 \pm 0.0006) c / \mu \mathrm{M}+(0.0462 \pm 0.0240)$ for the activated GCE and as $I_{p} / \mathrm{mA} \mathrm{cm}^{-2}=(0.0344 \pm 0.0003)$ $c / \mu \mathrm{M}+(0.0004 \pm 0.0040)$ for the $\beta$-CD-modified GCE, with correlation coefficients $>0.99$. Using the slopes of these equations, the sensitivity of the measurement, was calculated as $32.7 \pm 0.6 \mu \mathrm{A} \mathrm{cm}^{-2} \mu \mathrm{M}^{-1}$ for the activated GCE and as $34.4 \pm 0.3 \mu \mathrm{A} \mathrm{cm}^{-2} \mu \mathrm{M}^{-1}$ for the $\beta$-CD-modified
GCE. The corresponding LOD values were estimated as $(9.8 \pm 0.4) \times 10^{-8} \mathrm{M}$ and $(9.7 \pm 0.4) \times 10^{-8} \mathrm{M}$, respectively, using the standard deviation of the blank and the sensitivity. Clearly, there is no significant difference between the $\beta$-CDmodified and activated GCE in the electrochemical sensing of acetaminophen.

These sensing parameters compare reasonably well, with a number of previous investigations, where multiwalled carbon nanotubes (MWCNTs) [49], graphene [9] and various nanoparticles (NPs) [50], and other electrode modifications, such as bismuth [51], were used. While the linear region is somewhat lower than some of the reported values (Table S1 (supplementary data)) that have linear ranges extending from 5 to $200 \mu \mathrm{M}$ [49], the sensitivities are high at 32.7 and $34.4 \mu \mathrm{A} \mathrm{cm}^{-2} \mu \mathrm{M}^{-1}$. These compare very favourably with reported values of $37.28 \mu \mathrm{A} \mathrm{mM}^{-1}$ [30], $0.618 \mu \mathrm{A}$ $\mathrm{cm}^{-2} \mu \mathrm{M}^{-1}$ [23] and $0.15 \mu \mathrm{A} \mu \mathrm{M}^{-1}$ [26].

The selectivity of the detection of acetaminophen at the $\beta$-CD/GCE was studied using caffeine, ascorbic acid, aspirin, uric acid and sorbate as interference compounds. A representative differential pulse voltammogram is shown in Fig. 9, which was recorded in a neutral solution with $0.025 \mathrm{mM}$ acetaminophen and $0.05 \mathrm{mM}$ caffeine, $0.05 \mathrm{mM}$ aspirin and $0.05 \mathrm{mM}$ ascorbic. Here, it is clearly seen that at these concentrations the oxidation of acetaminophen is not influenced by the added interferences, with the oxidation of caffeine observed at $1.28 \mathrm{~V}$ vs. $\mathrm{Ag} / \mathrm{AgCl}$ and the oxidation of ascorbic acid appearing as a broad wave centred
Fig. 9 a DPV recorded in $0.025 \mathrm{mM}$ acetaminophen with $0.05 \mathrm{mM}$ ascorbic acid, $0.05 \mathrm{mM}$ caffeine and $0.05 \mathrm{mM}$ aspirin in a phosphate buffer, at a $\mathrm{pH}$ of 7.0, b acetaminophen (Acet.) peak currents recorded for $0.025 \mathrm{mM}$ acetaminophen in the absence and presence of various interference compounds (0.05 mM).
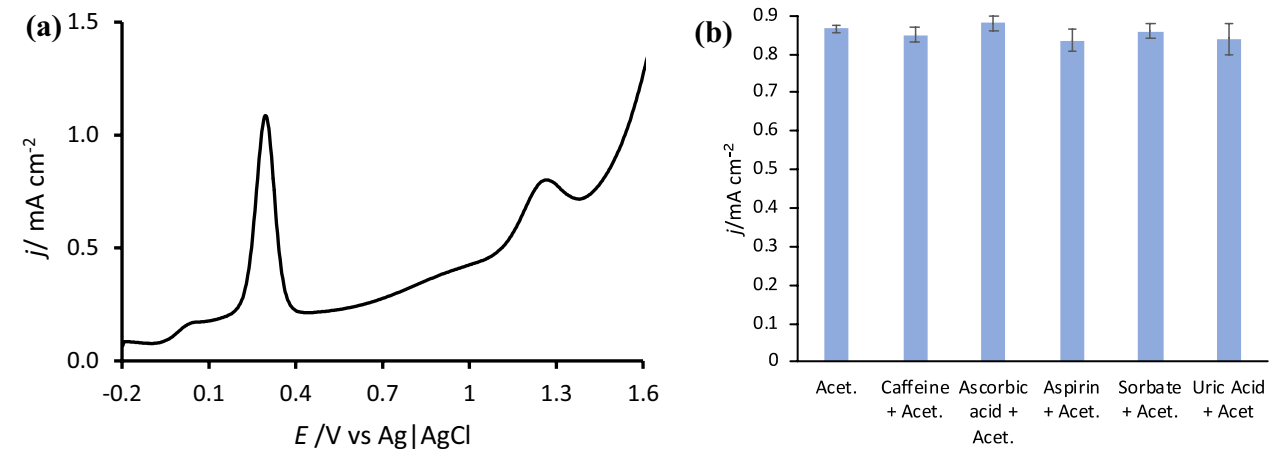
at $0.04 \mathrm{~V}$ vs. $\mathrm{Ag} / \mathrm{AgCl}$, with no overlap with the oxidation wave of acetaminophen. Indeed, the peak currents obtained for acetaminophen in the absence and presence of the interferences were very similar, indicating good selectivity. This is illustrated in Fig. 9(b), where the peak current obtained for acetaminophen is shown in the absence and presence of $0.05 \mathrm{mM}$ caffeine, $0.05 \mathrm{mM}$ aspirin, $0.05 \mathrm{mM}$ ascorbic, $0.05 \mathrm{M}$ uric acid and $0.05 \mathrm{mM}$ sorbate. Furthermore, it is evident from Fig. 9(a) that the sensor has applications in the simultaneous sensing and detection of acetaminophen and caffeine. This good selectivity is partially related to the fact that many of the interferents oxidise at potentials that are different to the $E_{p}$ value of acetaminophen, but it may also be connected with adsorption of the acetaminophen, partially blocking the interferents from the surface. However, on increasing the concentration of the interferents, interference was observed with uric acid and when a tenfold excess of UA was employed, the acetaminophen peak current was reduced to $0.65 \mathrm{~mA} \mathrm{~cm}^{-2}$, with the emergence of the UA oxidation wave, corresponding to a $25 \%$ reduction in the peak current.

The ability of the sensor to detect acetaminophen in a commercial pharmaceutical tablet containing caffeine was tested using a standard spiking and recovery experiment. The tablet was dissolved in the phosphate buffer and made up to different concentrations. No other treatments were carried out, with the samples containing various excipients. The sensor was then employed in these real samples and the currents recorded were compared to the predicted values obtained using the acetaminophen standards. The $\%$ recovery was very good with the lower added concentrations (97 to $100 \%$, with additions varying between 0.24 and $1.90 \mu \mathrm{M})$, but with the much higher concentrated spikes the recovery values become lower $(92.5 \%$ with a spike of $19.9 \mu \mathrm{M})$ (Table S2). Nevertheless, these data do illustrate the satisfactory selectively of the sensor in a complex solution with caffeine and other excipients.

\section{Comparison of the $\beta-C D$ and activated glassy carbon}

It is clear that activation of the GCE and its modification in the presence of $\beta$-CD alters the oxidation of acetaminophen from the normally diffusion-controlled reaction to an adsorption-controlled event. Furthermore, the electrogenerated $\mathrm{N}$-acetyl benzoquinone imine is protected from hydrolysis through adsorption at the modified electrodes. Similar data were obtained using both the activated GCE and the $\beta$-CD-modified GCE, clearly showing that while the $\beta-C D$ may play a minor role, it is the activated GCE that contributes to the enhanced detection of acetaminophen. It is well known that the electrooxidation of carbon-based electrodes polarised beyond the oxygen evolution reaction, results in the formation of oxygen-containing groups [52].
At these high anodic potentials, $\mathrm{OH}^{\bullet}$ radicals are produced which then attack the surface carbon atoms at defect sites leading to the breakage of $\mathrm{C}-\mathrm{C}$ bonds, with the formation of various oxygenated groups. Microcrystalline graphite with oxide-enriched edge planes are formed, enhancing the electrochemical properties of the activated electrode [52]. It appears that these events are responsible for the enhanced electrochemical oxidation and sensing of acetaminophen, providing a very simple, low cost and environmentally acceptable electrode modification approach. Indeed, this activation is likely to play a significant role in the sensing events of several studies where the GCE was polarised to high potentials during its modification [53-56].

\section{Conclusion}

In attempting to electropolymerise $\beta$-CD at a GCE surface, it was found that the electrochemical window normally employed in the electropolymerisation of $\beta$-CD results in the activation and oxidation of the GCE surface. This activation results in the enhanced detection of acetaminophen with evidence that acetaminophen is adsorbed at the activated surface, resulting in the protection of the acetaminophen oxidation product from hydrolysis. The presence of the $\beta-C D$ in the phosphate solution during the activation of the GCE has little influence on the enhancement of the detection of acetaminophen. Indeed, similar rate constants, LOD values and sensitivities were observed with the simple activation of the GCE in the absence of the $\beta-C D$. These results clearly show that the GCE is altered and activated during electrode modifications that require the application of high potentials in the vicinity of the oxygen evolution reaction. This activation is likely to contribute to the increased detection reported in a number of studies.

Supplementary information The online version contains supplementary material available at https://doi.org/10.1007/s10008-021-05044-3.

Funding Open Access funding provided by the IReL Consortium. The authors wish to acknowledge support from the Erasmus + Mobility Consortium, Calabria 2020 Plus, Rif. 2018-1-IT02-KA103-047660 and the Irish Research Council, award number GOIPG/2020/657.

Open Access This article is licensed under a Creative Commons Attribution 4.0 International License, which permits use, sharing, adaptation, distribution and reproduction in any medium or format, as long as you give appropriate credit to the original author(s) and the source, provide a link to the Creative Commons licence, and indicate if changes were made. The images or other third party material in this article are included in the article's Creative Commons licence, unless indicated otherwise in a credit line to the material. If material is not included in the article's Creative Commons licence and your intended use is not permitted by statutory regulation or exceeds the permitted use, you will 
need to obtain permission directly from the copyright holder. To view a copy of this licence, visit http://creativecommons.org/licenses/by/4.0/.

\section{References}

1. Toms L, McQuay HJ, Derry S, Moore RA, Moore M (2008) Single dose oral paracetamol (acetaminophen) for postoperative pain in adults. Cochrane Database Syst Rev 4:CD004602

2. Bertolini A, Ferrari A, Ottani A, Guerzoni S, Tacchi R, Leone S (2006) Paracetamol: new vistas of an old drug. CNS Drug Rev $12: 250-275$

3. Song H, Chen TS (2001) P-Aminophenol-induced liver toxicity: tentative evidence of a role for acetaminophen. J Biochem Mol Toxicol 15:34-40

4. Bosch ME, Sánchez AJR, Rojas FS, Ojeda CB (2006) Determination of paracetamol: historical evolution. J Pharm Biomed Anal 42:291-321

5. Cunha RR, Chaves SC, Ribeiro MMAC, Torres LMFC, Muñoz RAA, Santos WTPD, Richter EM (2015) Simultaneous determination of caffeine, paracetamol, and ibuprofen in pharmaceutical formulations by high-performance liquid chromatography with UV detection and by capillary electrophoresis with conductivity detection. J Sep Sci 38:1657-1662

6. Mallah MA, Sherazi STH, Bhanger MI, Mahesar SA, Bajeer MA (2015) A rapid Fourier-transform infrared (FTIR) spectroscopic method for direct quantification of paracetamol content in solid pharmaceutical formulations. Spectrochim. Acta - Part A Mol. Biomol Spectrosc 141:64-70

7. Griffen J, Owen A, Matousek P (2015) Comprehensive quantification of tablets with multiple active pharmaceutical ingredients using transmission Raman spectroscopy-a proof of concept study. J Pharm Biomed Anal 115:277-282

8. Li Z-Y, Gao D-Y, Wu Z-Y, Zhao S (2020) Simultaneous electrochemical detection of levodapa, paracetamol and 1-tyrosine based on multi-walled carbon nanotubes. RSC Adv 10:14218-14224

9. Kang X, Wang J, Wu H, Liu J, Aksay IA, Lin Y (2020) A graphenebased electrochemical sensor for sensitive detection of paracetamol. Talanta 81:754-759

10. Zhang X, Wang K-P, Zhang L-N, Zhang Y-C, Shen L (2018) Phosphorus-doped graphene-based electrochemical sensor for sensitive detection of acetaminophen. Anal Chim Acta 1036:26-32

11. Fan FY, Liu J-H, Lu H-T, Zhang Q (2011) Electrochemical behavior and voltammetric determination of paracetamol on Nafion/ $\mathrm{TiO}_{2}$-graphene modified glassy carbon electrode. Colloids Surfaces B Biointerfaces 85:289-292

12. Yi, Y, Fiston MN, Zhang D, Zhu G (2020) Nitrogen-doped carbon black/reduced graphene oxide nanohybrids for simultaneous electrochemical determination of hydroquinone and paracetamol. J Electrochem Soc 167:066510

13. Dou N, Qu J (2020) Simultaneous detection of 4-aminophenol and paracetamol using a glassy carbon electrode modified with graphene oxide, $\mathrm{TiO}_{2}$ and gold nanoparticles. J Electrochem.Soc 167:066512

14. Goyal RN, Gupta VK, Chatterjee S (2010) Voltammetric biosensors for the determination of paracetamol at carbon nanotube modified pyrolytic graphite electrode. Sensors Actuators, B Chem 149:252-258

15. Kachoosangi RT, Wildgoose GG, Compton RG (2008) Sensitive adsorptive stripping voltammetric determination of paracetamol at multiwalled carbon nanotube modified basal plane pyrolytic graphite electrode. Anal Chim Acta 618:54-60

16. Habibi B, Jahanbakhshi M, Pournaghi-Azar MH (2011) Differential pulse voltammetric simultaneous determination of acetaminophen and ascorbic acid using single-walled carbon nanotubemodified carbon-ceramic electrode. Anal Biochem 411:167-175

17. Raoof JB, Chekin F, Ojani R, Barari S, Anbia M, Mandegarzad S (2012) Synthesis and characterization of ordered mesoporous carbon as electrocatalyst for simultaneous determination of epinephrine and acetaminophen. J Solid State Electrochem 16:3753-3760

18. Li J, Liu J, Tan G, Jiang J, Peng S, Deng M, Qian D, Feng Y, Liu Y (2014) High-sensitivity paracetamol sensor based on Pd/ graphene oxide nanocomposite as an enhanced electrochemical sensing platform. Biosens Bioelectron 54:468-475

19. Yang G, Wang L, Jia J, Zhou D, Li D (2012) Chemically modified glassy carbon electrode for electrochemical sensing paracetamol in acidic solution. J Solid State Electrochem 16:2967-2977

20. Yang G, Yu L, Jia J, Zhao Z (2012) 4-Aminobenzoic acid covalently modified glassy carbon electrode for sensing paracetamol at different temperatures. J Solid State Electrochem 16:1363-1368

21. Saleem SJ, Guler M (2019) Electroanalytical determination of paracetamol using Pd nanoparticles deposited on carboxylated graphene oxide modified glassy carbon electrode. Electroanalysis 31:2187-2198

22. Pournaghi-Azar MH, Kheradmandi S, Saadatirad A (2010) Simultaneous voltammetry of paracetamol, ascorbic acid, and codeine on a palladium-plated aluminum electrode: Oxidation pathway and kinetics. J Solid State Electrochem 14:1689-1695

23. Liu B, Ouyang X, Ding Y, Luo L, Xu D, Ning Y (2016) Electrochemical preparation of nickel and copper oxides-decorated graphene composite for simultaneous determination of dopamine, acetaminophen and tryptophan. Talanta 146:114-121

24. Devaraj M, Saravanan R, Deivasigamani R, Gupta VK, Gracia F, Jayadevan $\mathrm{S}$ (2016) Fabrication of novel shape $\mathrm{Cu}$ and $\mathrm{Cu} /$ $\mathrm{Cu}_{2} \mathrm{O}$ nanoparticles modified electrode for the determination of dopamine and paracetamol. J Mol Liq 221:930-941

25. Vinay MM, Arthoba Nayaka Y (2019) Iron oxide $\left(\mathrm{Fe}_{2} \mathrm{O}_{3}\right)$ nanoparticles modified carbon paste electrode as an advanced material for electrochemical investigation of paracetamol and dopamine. $\mathrm{J}$ Sci Adv Mater Devices 4:442-450

26. Kumar M, Kumara Swamy BE, Reddy S, Zhao W, Chetana S, Gowrav Kumar V (2019) ZnO/functionalized MWCNT and Ag/ functionalized MWCNT modified carbon paste electrodes for the determination of dopamine, paracetamol and folic acid. J Electroanal Chem 835:96-105

27. Ashoka NB, Swamy BEK, Jayadevappa H, Sharma SC (2020) Simultaneous electroanalysis of dopamine, paracetamol and folic acid using $\mathrm{TiO}_{2}-\mathrm{WO}_{3}$ nanoparticle modified carbon paste electrode. J Electroanal Chem 859:113819

28. Houshmand M, Jabbari A, Heli H, Hajjizadeh M, Moosavi-Movahedi AA (2008) Electrocatalytic oxidation of aspirin and acetaminophen on a cobalt hydroxide nanoparticles modified glassy carbon electrode. J Solid State Electrochem 12:1117-1128

29. Goyal RN, Gupta VK, Oyama M, Bachheti N (2005) Differential pulse voltammetric determination of paracetamol at nanogold modified indium tin oxide electrode. Electrochem Commun 7:803-807

30. Wang L, Meng T, Fan Y, Chen C, Guo Z, Wang H, Zhang Y (2018) Electrochemical study of acetaminophen oxidation by gold nanoparticles supported on a leaf-like zeolitic imidazolate framework. J Colloid Interface Sci 524:1-7

31. Ye D, Xu Y, Luo L, Ding Y, Wang Y, Liu X (2012) LaNi 0.5Ti $0.5 \mathrm{O}_{3} / \mathrm{CoFe}_{2} \mathrm{O}_{4}$-based sensor for sensitive determination of paracetamol. J Solid State Electrochem 16:1635-1642 
32. Vidyadharan AK, Jayan D, Mary Nancy TE (2014) $\mathrm{Ni} 0.1 \mathrm{Co} 0.9 \mathrm{Fe}_{2} \mathrm{O}_{4}$-based electrochemical sensor for the detection of paracetamol. J Solid State Electrochem 18:2513-2519

33. Healy B, Yu T, da Silva Alves DC, Okeke C, Breslin CB (2021) Cyclodextrins as supramolecular recognition systems: applications in the fabrication of electrochemical sensors. Materials (Basel) 14:1668

34. Harley CC, Annibaldi V, Yu T, Breslin CB (2019) The selective electrochemical sensing of dopamine at a polypyrrole film doped with an anionic $\beta$-cyclodextrin. J Electroanal Chem 855:113614

35. Carrillo I, Quintana C, Esteva AM, Hernández L, Hernández P (2011) Self-assembled submonolayer of $\beta$-cyclodextrins on gold electrode for the selective determination of 4-aminobiphenyl. Electroanalysis 23:2862-2869

36. Tu X, Gao F, Ma X, Zou J, Yu Y, Li M, Qu F, Huang X, Lu L (2020) Mxene/carbon nanohorn/ $\beta$-cyclodextrin-metal-organic frameworks as high-performance electrochemical sensing platform for sensitive detection of carbendazim pesticide. J Hazard Mater 396:122776

37. Cui X, Yang B, Zhao S, Li X, Qiao M, Mao R, Wang Y, Zhao X (2020) Electrochemical sensor based on ZIF-8@dimethylglyoxime and $\beta$-cyclodextrin modified reduced graphene oxide for nickel(II) detection. Sensors Actuators, B Chem 315:128091

38. Pereira AC, Oliveira AEF, Bettio GB (2019) $\beta$-Cyclodextrin electropolymerization: mechanism, electrochemical behavior, and optimization. Chem Pap 73:1795-1804

39. Wayu MB, DiPasquale LT, Schwarzmann MA, Gillespie SD, Leopold MC (2016) Electropolymerization of $\beta$-cyclodextrin onto multi-walled carbon nanotube composite films for enhanced selective detection of uric acid. J Electroanal Chem 783:192-200

40. Wei M, Geng X, Liu Y, Long H, Du J (2019) A novel electrochemical sensor based on electropolymerized molecularly imprinted polymer for determination of luteolin. J Electroanal Chem 842:184-192

41. Peng R, Gao Y, Chen W (2021) Determination of chloramphenicol by a new electrochemically activated glassy carbon electrode in sodium sulfate medium. J Electrochem Soc168:067509

42. Huang D, Cheng Y, Xu H, Zhang H, Sheng L, Xu H, Liu Z, Wu H, Fan S (2015) The determination of uric acid in human body fluid samples using glassy carbon electrode activated by a simple electrochemical method. J Solid State Electrochem 19:435-443

43. Holloway AF, Wildgoose GG, Compton RG, Shao L, Green MLH (2008) The influence of edge-plane defects and oxygen-containing surface groups on the voltammetry of acid-treated, annealed and "super-annealed" multiwalled carbon nanotubes. J Solid State Electrochem 12:1337-1348

44. Liu X, Wang Y, Zhan L, Qiao W, Liang X, Ling L (2011) Effect of oxygen-containing functional groups on the impedance behavior of activated carbon-based electric double-layer capacitors. J Solid State Electrochem 15:413-419
45. Tenent RC, Wipf DO (2009) Local electron transfer rate measurements on modified and unmodified glassy carbon electrodes. J Solid State Electrochem 13:583-590

46. Farhat A, Keller J, Tait S, Radjenovic J (2017) Assessment of the impact of chloride on the formation of chlorinated by-products in the presence and absence of electrochemically activated sulfate. Chem Eng J 330:1265-1271

47. Yi Y, Weinberg G, Prenzel M, Greiner M, Heumann S, Becker S, Schlögl R (2017) Electrochemical corrosion of a glassy carbon electrode. Catal Today 295:32-40

48. Rajakumaran R, Sukanya R, Chen SM, Karthik R, Breslin CB, Shafi PM (2021) Synthesis and characterization of pyrochloretype praseodymium stannate nanoparticles: an effective electrocatalyst for detection of nitrofurazone drug in biological samples. Inorg Chem 60:2464-2476

49. Ghica ME, Wintersteller Y, Brett CMA (2013) Poly(brilliant green)/carbon nanotube-modified carbon film electrodes and application as sensors. J Solid State Electrochem 17:1571-1580

50. Manjunatha KG, Swamy BEK, Madhuchandra HD, Vishnumurthy KA (2021) Synthesis, characterization and electrochemical studies of titanium oxide nanoparticle modified carbon paste electrode for the determination of paracetamol in presence of adrenaline. Chem Data Collect 31:100604

51. van der Horst C, Silwana B, Gil E, Iwuoha E, Somerset V (2020) Simultaneous detection of paracetamol, ascorbic acid, and caffeine using a bismuth-silver nanosensor. Electroanalysis 32:3098-3107

52. Rana A, Baig N, Saleh TA (2019) Electrochemically pretreated carbon electrodes and their electroanalytical applications - a review. J Electroanal Chem 833:313-332

53. Zhang Z, Gu S, Ding Y, Shen M, Jiang L (2014) Mild and novel electrochemical preparation of $\beta$-cyclodextrin/graphene nanocomposite film for super-sensitive sensing of quercetin. Biosens Bioelectron 57:239-244

54. Sun Y, Wei T, Jiang M, Xu L, Xu Z (2018) Voltammetric sensor for chloramphenicol determination based on a dual signal enhancement strategy with ordered mesoporous carbon@ polydopamine and $\beta$-cyclodextrin. Sensors Actuators, B Chem 255:2155-2162

55. Jiang Z, Li G, Zhang M (2016) Electrochemical sensor based on electro-polymerization of $\beta$-cyclodextrin and reduced-graphene oxide on glassy carbon electrode for determination of gatifloxacin. Sensors Actuators, B Chem 228:59-65

56. Ren W, Luo HQ, Li NB (2006) Simultaneous voltammetric measurement of ascorbic acid, epinephrine and uric acid at a glassy carbon electrode modified with caffeic acid. Biosens Bioelectron 21:1086-1092

Publisher's Note Springer Nature remains neutral with regard to jurisdictional claims in published maps and institutional affiliations. 